\title{
Endoscopic ultrasonography-guided photodynamic therapy for recurrent intraductal papillary mucinous neoplasm of the pancreas
}

Recurrence rates after partial pancreatectomy in patients with a noninvasive intraductal papillary mucinous neoplasm (IPMN) of the pancreas are reported as being $5.4 \%$ to $10.7 \%$ [1-3]. A recent case demonstrated the possibility of using photodynamic therapy (PDT) as an alternative therapeutic option for IPMN [4]. Herein, we present a patient who was treated with endoscopic ultrasonography (EUS)-guided PDT, which was used as an alternative, minimally invasive option for recurrent IPMN of the pancreas.

A 50-year-old man was admitted with recurrent pancreatitis. He had a history of distal pancreatectomy for combinedtype IPMN 2 years previously, and the resection margins had been positive. A computed tomography (CT) scan revealed swelling of the remnant pancreas with a 13-mm hypodense lesion and prominent main pancreatic duct (MPD) dilatation. EUS-guided needle biopsy of a 5-mm nodular lesion in the MPD and a $15-\mathrm{mm}$ hypoechoic mass in the stump demonstrated recurrent IPMN with low grade dysplasia ( $>$ Fig. 1 ). The patient re- fused to undergo total pancreatectomy, so we decided to perform EUS-guided PDT ( Video 1) [5].

Photolon (a chlorin e6 derivative; Belmedpreparaty, Belarus) was administered at a dose of $2.5 \mathrm{mg} / \mathrm{kg}$, 3 hours be- fore the procedure. The flexible laserlight probe (a quartz core and polymer cladding; PhotoGlow Inc., Yarmouth, Massachusetts, USA) was preloaded inside a 19G EUS fine needle aspiration (FNA) needle (Cook Endoscopy, Winston-

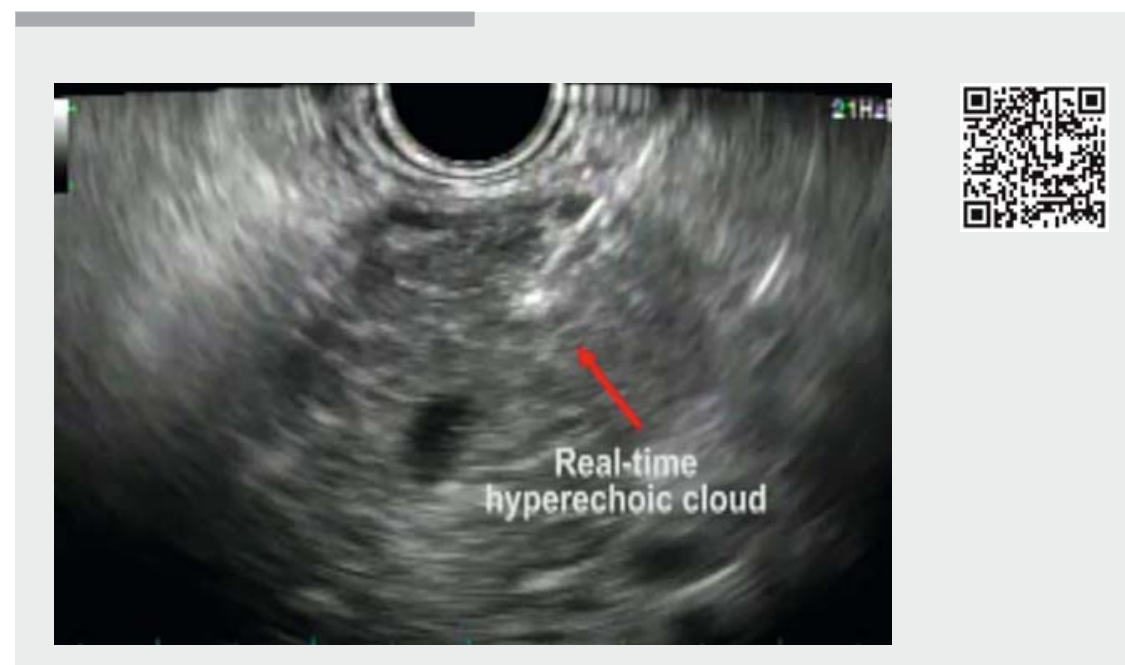

Video 1 Endoscopic ultrasonography-guided photodynamic therapy for recurrent noninvasive intraductal papillary mucinous neoplasm (IPMN) of the pancreas following a previous distal pancreatectomy.
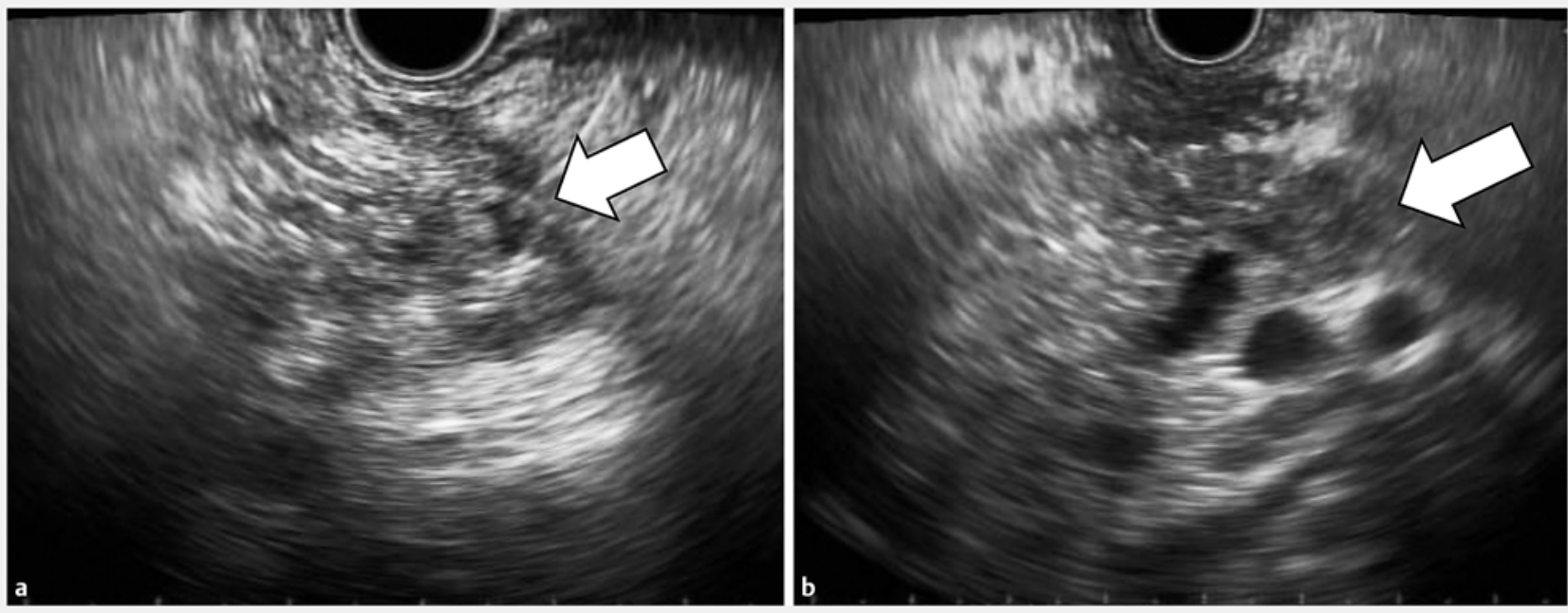

Fig. 1 Endoscopic ultrasonography (EUS) image showing: a a 5-mm nodular lesion in the main pancreatic duct; $\mathbf{b}$ a 15-mm hypoechoic mass in the stump. 

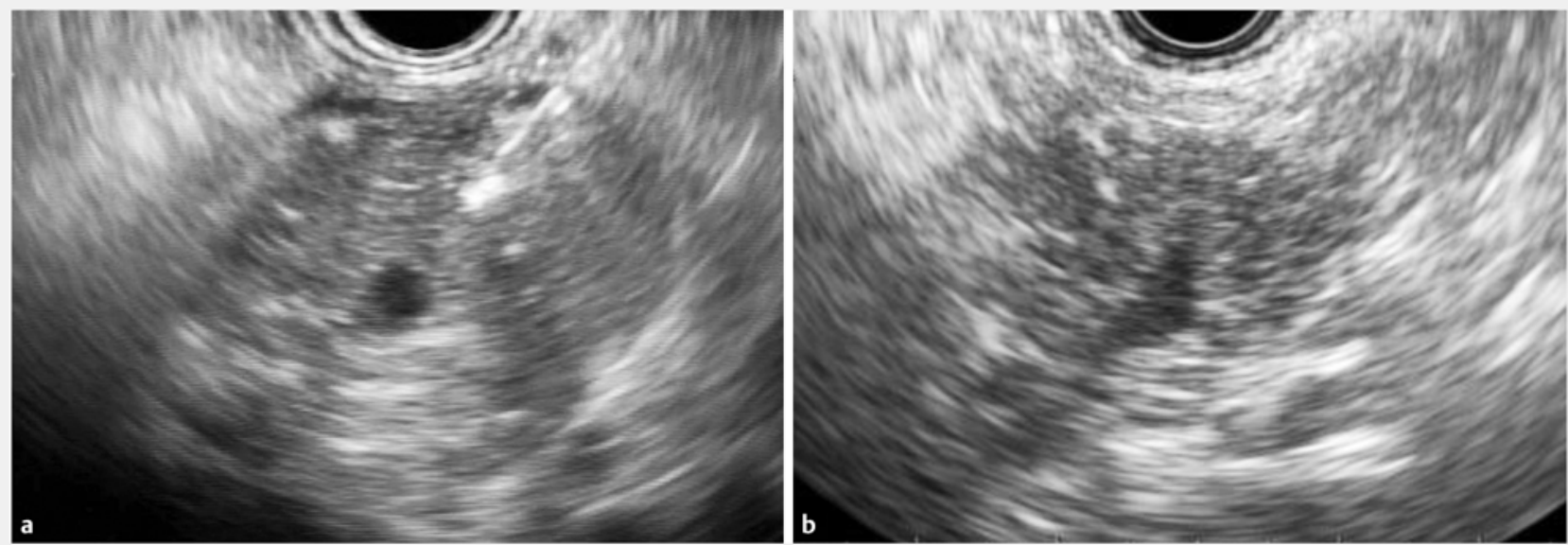

- Fig. 2 Endoscopic ultrasonography (EUS) images showing: a a hyperechoic cloud in the area surrounding the laser diffuser tip during EUSguided photodynamic therapy (PDT); b no evidence of tumor recurrence 2 years after the PDT.

Salem, North Carolina, USA) and was inserted into the recurrent tumor. The tumor was then illuminated with a wavelength of $660 \mathrm{~nm}$ ( $\vee$ Fig. 2 a). The energy dose was $100 \mathrm{~J} / \mathrm{cm}$ of the diffuser length; the power of irradiation was $400 \mathrm{~mW} / \mathrm{cm}$ of the diffuser length in each procedure. The total irradiation time in each needle pass was 250 seconds.

At follow-up EUS 2 years after the PDT, there was no evidence of recurrence ( $\vee$ Fig.2b). EUS-guided biopsy at the pancreas stump showed only acinar cells and interstitial fibrosis. The patient experienced no further episodes of pancreatitis during the follow-up period.

This study was approved by the Institutional Review Board of Asan Medical Center (IRB number: 2015-0111).

Endoscopy_UCTN_Code_TTT_1AS_2AD

Competing interests

None

The Authors

Sun-Ho Lee, Hoonsub So*, Seungwhan Shin, Nah Kyum Lee, Do Hyun Park

Division of Gastroenterology, Department of Internal Medicine, University of Ulsan College of Medicine, Asan Medical Center, Seoul, South Korea

\footnotetext{
* Contributed equally to this article
}

Corresponding author

\section{Do Hyun Park, MD, PhD}

Division of Gastroenterology, Department of Internal Medicine, University of Ulsan College of Medicine, Asan Medical Center, 88, Olympic-Ro 43-Gil, Songpa-Gu, Seoul 05505, Korea

Fax: +82-2-4760824

dhpark@amc.seoul.kr

\section{References}

[1] Kang M], Jang JY, Lee KB et al. Long-term prospective cohort study of patients undergoing pancreatectomy for intraductal papillary mucinous neoplasm of the pancreas: implications for postoperative surveillance. Ann Surg 2014; 260: 356-363

[2] Passot G, Lebeau R, Hervieu V et al. Recurrences after surgical resection of intraductal papillary mucinous neoplasm of the pancreas: a single-center study of recurrence predictive factors. Pancreas 2012; 41: 137 141

[3] Schnelldorfer T, Sarr MG, Nagorney DM et al. Experience with 208 resections for intraductal papillary mucinous neoplasm of the pancreas. Arch Surg 2008; 143: 639-646; discussion 646

[4] Topazian M, Zhong N, Baron TH et al. Photodynamic therapy of intraductal papillary mucinous neoplasm. Endoscopy 2012; 44: $213-215$

[5] Choi JH, Oh D, Lee JH et al. Initial human experience of endoscopic ultrasound-guided photodynamic therapy with a novel photosensitizer and a flexible laser-light catheter. Endoscopy 2015; 47: 1035-1038

\section{Bibliography}

DOI https://doi.org/10.1055/s-0043-117938

Published online: 13.9.2017

Endoscopy 2017; 49: 1107-1108

(c) Georg Thieme Verlag KG

Stuttgart $\cdot$ New York

ISSN 0013-726X

\section{ENDOSCOPY E-VIDEOS \\ https:/|eref.thieme.de/e-videos}

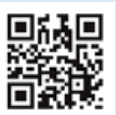

Endoscopy E-Videos is a free access online section, reporting on interesting cases and new techniques in gastroenterological endoscopy. All papers include a high quality video and all contributions are freely accessible online.

This section has its own submission website at https://mc.manuscriptcentral.com/e-videos 